\title{
Knowledge, attitude and practice about STD/ HIV AIDS among the health attendant staffs of a Tertiary Level hospital of Eastern Nepal
}

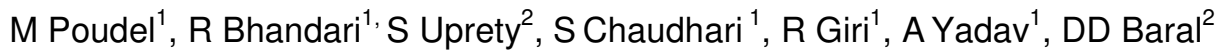 \\ Department of General Practices and Emergency Medicine ${ }^{1}$, School of Public Health and Community \\ Medicine ${ }^{2}$ \\ B.P. Koirala Institute of Health Sciences, Dharan, Nepal
}

\begin{abstract}
Background: Knowledge, attitudes and practices (KAP) surveys are possibly the most frequently used studies in health-seeking behaviour research. Health care workers serve as key players in the prevention and management of diseases. Their perceptions, attitudes and practices have implications for the management of diseases in both health centers and communities. Objective: To assess knowledge, attitude and practice towards STDs among health attendant staffs (health aids and health attendants) of BPKIHS. Methods: This is a descriptive cross sectional study. The study population was Health attendants and Health aids workers working in different departments of BPKIHS. Modified structured questionnaire was used for data collection. SPSS version 11.5 was used for data entry and analysis. Results: 180 Health attendants and Health aids working in different departments of BPKIHS participated in the study. $29 \%$ belonged to $30-34$ age groups. $86 \%$ of study population had heard about STD/HIV/AIDS. $29 \%$ expressed that having intercourse without using condoms is known as unprotected sex. Unprotected sexual habits (40.6\%), using mask, gloves while working (30\%) were methods listed for prevention of transmission of STDs/HIV/AIDS. Conclusion: Majority were from 30-39 years group.86\% had heard about STDs/HIV/AIDS. The commonest method to protect from STDs/HIV/AIDS were listed as avoiding multiple sex partners and use gloves and mask while working
\end{abstract}

Keywords: BPKIHS, health attendant, health-seeking behaviour.

\footnotetext{
Address for correspondence

Dr. Masum Poudel

Associate professor

Department of General Practices and Emergency Medicine

B.P. Koirala Institute of Health Sciences, Dharan

Email: drmasum@yahoo.com
} 


\section{Introduction}

The term sexually transmitted diseases denote disorders that are principally spread by intimate contact ${ }^{1}$. These diseases are not merely acute illnesses, but may lead to serious complications ${ }^{2,3}$. The risk of HIV spread and acquirement have both increased by a factor of 10 in the existence of untreated STDs. ${ }^{4}$ HIV/AIDS is a global epidemic and is considered one of the greatest public health problems both in developed and developing world. Though Nepal is considered as a "lowincidence" country in terms of HIV infection, recent sero-prevalence data suggest that HIV/STIs infections have increased significantly in the last five years which is attributable to an active sex trades, low levels of condom use, increasing number of HIV among intravenous drug users and substantial male labour migration..$^{5,6,7}$ It has been demonstrated that increased knowledge about AIDS is not a predictor for behavioral change, although knowledge about the disease is a prerequisite for change. , $^{8,10,11}$ The study done by Husain MFA et $\mathrm{al}^{12}$ showed that knowledge and attitudes was reasonably good but improvement is required with respect to management of STDs \& HIV. In other study ${ }^{13}$ in rural hospitals in South Africa among health workers showed that the majority of the sample had medium level of knowledge about HIV/AIDS and about 75\% had positive attitude towards the caring for patients with HIV/AIDS and 5.9\% had very negative attitude. Uprety $D$ et.al. ${ }^{14}$ showed that STIs and HIV/AIDS are high, although the level of knowledge seems to differ according to education, gender, and area of residence

To formulate the preventative strategy of nation towards HIV/AIDS/STD, KAP should be assessed at different levels. The health aids and health attendants are assumed to have good knowledge and practice with regards to transmission of HIV and STDs as they interact with them on a daily basis and form a vulnerable group. So far the KAP surveys/ cross sectional studies of the country haven't touched on this. So, this study is expected to give information on this particular group of workers.

\section{Methods}

This is a cross sectional study conducted by department of General Practice and Emergency Medicine and School of Public Health and Community Medicine of BPKIHS from July-September 2012. Sample unit were all health attendants and health aids working at different departments of B.P. Koirala Institute of Health Sciences. Health aids and attendants are non-technical supporting staffs working in hospital for patient transport, waste management, cleaning and helping nursing staffs and doctors. According to the department of personal administration record 
there are a total of 200 health aids and health attendants are currently employed. A questionnaire in Nepali was developed focusing on knowledge, attitudes, and practice related questions on STD/HIV/ AIDS. Both open ended and closed questions were included. The data was collected employing one on one interview techniques by the researchers maintaining total privacy and confidentiality. The following variables were studied:

Knowledge: source of information, definition, transmission, symptoms/presentation, prevention.

Attitude: sexual practice, working with high risk or infected colleagues, condom use participate in awareness programmes, sex education in schools.

Practice: health seeking behaviour, condom use, needle pricks, use of standard precautions related to STDs/HIV/AIDS.
Collected data was checked, rechecked and edited at the end of each day of data collection. Coding and categorization was done. SPSS version 11.5 computer software was used for data entry and analysis. Prior to entry in SPSS program a database was formed mentioning, label, value and criteria of the variables. The data were summarized by frequency, percentage. Correlations statistics was done to see correlation among knowledge, attitude and practices.

Ethical clearance was obtained from ethical board of BPKIHS. Informed consent was taken from the each respondent prior the study, by explaining the objectives of the study. Their right of refusal to participate in this study was respected. The confidentiality of the information was maintained and used for the purpose of the study only.

\section{Results}

The sample size was 200 with a response rate of $90 \%(180)$.

Table 1: Socio-demographic profile of study population $(n=180)$

\begin{tabular}{|l|l|l|}
\hline \multicolumn{1}{|c|}{ Characteristics } & \multicolumn{1}{|c|}{ Frequency $(\mathrm{n})$} & \multicolumn{1}{c|}{ Percentage (\%) } \\
\hline 1. Age in years & & 2.8 \\
$20-24$ & 5 & 17.8 \\
$25-29$ & 32 & 28.3 \\
$30-34$ & 51 & 15.6 \\
$35-39$ & 28 & 14.4 \\
$40-44$ & 26 & \\
\hline
\end{tabular}




\begin{tabular}{|c|c|c|}
\hline 45 and above & 38 & 21.1 \\
\hline \multicolumn{3}{|l|}{ 2. Gender } \\
\hline Male & 61 & 33.9 \\
\hline Female & 119 & 66.1 \\
\hline \multicolumn{3}{|l|}{ 3. Religion } \\
\hline Hindu & 158 & 87.8 \\
\hline Buddhism & 11 & 6.1 \\
\hline Others & 11 & 6.1 \\
\hline \multicolumn{3}{|l|}{ 4. Ethnicity } \\
\hline Brahmin & 32 & 17.8 \\
\hline Chettri & 27 & 15.0 \\
\hline Dalit & 45 & 25.0 \\
\hline Hill janjati & 47 & 26.1 \\
\hline Teraijanjati & 29 & 16.1 \\
\hline \multicolumn{3}{|l|}{ 5. Language spoken } \\
\hline Nepali & 138 & 76.7 \\
\hline Rai/Limbu & 10 & 5.6 \\
\hline Maithili & 19 & 10.6 \\
\hline Others & 13 & 7.2 \\
\hline \multicolumn{3}{|l|}{ 6. Marital status } \\
\hline Married & 166 & 92.2 \\
\hline Divorce & 3 & 1.7 \\
\hline Single & 11 & 6.1 \\
\hline \multicolumn{3}{|l|}{ 7. Literacy status } \\
\hline Illiterate & 21 & 11.7 \\
\hline Primary & 55 & 30.6 \\
\hline Secondary & 102 & 56.7 \\
\hline Higher secondary and above & 2 & 1.1 \\
\hline \multicolumn{3}{|l|}{ 8. Years worked experiences } \\
\hline $1-14$ years & 134 & 74.4 \\
\hline 15 years and above & 46 & 25.6 \\
\hline 9. Heard about STDs/HIV/AIDS & & \\
\hline
\end{tabular}




\begin{tabular}{|l|l|l|}
\hline Yes & 155 & 86.1 \\
No & 25 & 13.9 \\
\hline
\end{tabular}

Table 1 shows the socio demographic descriptors of the population studied. $28.3 \%$ of the study population belonged to 30-34 age group; the mean age of the study population was 36.77 (SD 9.028). Females were predominately more $(61.1 \%)$ than males $(33.9 \%)$. Majority of them were of Hindu religion (87 \%).The distribution of study population by ethnicity showed that hill Janjati (Rai, Limbu, Gurung, Magar) were 26.1\%, Dalits (BK, Pariyar, Musar) were 25.0\%, plains (terai) Janjati (Tharu, Shah, Yadav) $16.1 \%$, Brahmin $17.8 \%$ and Chhetri $15.0 \%$.

Majority $(92.2 \%)$ of the respondents were married. Literacy status showed that majority were literate up to secondary level (56.7\%), only $11.7 \%$ were illiterate. Classified by work experience, $74.4 \%$ had worked here above 14 years. $86 \%$ of study population had heard about STDs/HIV/AIDS.

\section{Table 2: Knowledge regarding STDs/HIV/AIDS among study population*}

\begin{tabular}{|l|l|l|}
\hline \multicolumn{1}{|c|}{ Characteristics } & Frequency $(\mathrm{n})$ & ${\text { Percentage }(\%)^{*}}^{*}$ \\
\hline 1. What do you understand by unprotected sex? & & \\
Without using condom while having sex & 52 & 28.9 \\
Multiple sex partners & 51 & 28.3 \\
Bad works & 4 & 2.2 \\
Don't know & 65 & 36.1 \\
Infectious diseases & 8 & 4.4 \\
\hline 2. What do you understand by sexually transmitted & & \\
disease? & & \\
Unprotected sex without using Family planning & 75 & 41.7 \\
Methods & 42 & 23.3 \\
Infectious disease(HIV/AIDS, Hep B Syphilis) & 5 & 2.8 \\
Itching over genital organ & 2 & 1.14 \\
Diseases transmitted by blood & 43 & 23.9 \\
Don't know & & \\
\hline 3.Which are sexually transmitted diseases & & \\
\hline
\end{tabular}




\begin{tabular}{|l|l|l|}
\hline HIV/AIDS & 117 & 65.0 \\
Don't Know & 41 & 22.8 \\
Syphilis & 46 & 25.6 \\
Hepatitis B & 25 & 13.9 \\
Gonorrhea & 23 & 12.8 \\
Leprosy & 4 & 2.2 \\
\hline 4. Causes of STD/HIV/AIDS & & \\
Don't Know & 110 & 61.1 \\
Who have multiple sex partners & 44 & 24.4 \\
Recurrent genitourinary problem & 53 & 29.4 \\
\hline 5. Symptoms of STDs/HIV/AIDS & & \\
Genitourinary symptoms & 77 & 42.8 \\
Weight loss ,weakness loss of appetites & 58 & 32.2 \\
Prolong diarrhea/wound infection & 36 & 20.0 \\
Prolong high grade fever & 19 & 10.6 \\
Don't Know & 66 & 36.7 \\
\hline 6. How STDs/HIV/AIDS can transmitted to others & & \\
From unprotected sex & 110 & 61.1 \\
Via Syringe & 94 & 52.2 \\
Through blood transfusion & 110 & 61.1 \\
Don't know & 15 & 8.3 \\
From mother to child & 4 & 2.2 \\
Drinking and smoking with infected persons & 3 & 1.7 \\
\hline
\end{tabular}

*\% 100 because of multiple responses

Table 2 shows knowledge regarding definition of unprotected sex and causes of STDs/HIV/AIDS. Unprotected sex was defined as sexual intercourse without using condom by $29 \%$ followed by sex with multiple partners by $28 \%$. More than one third respondents said they didn't know "what is unprotected sex". Causes listed for
STDs/HIV/AIDS were multiple genitourinary infections $(29 \%)$ followed by multiple sex partners $(24.4 \%)$. Symptoms were listed as genitourinary symptoms (42.8\%) like itching over genital region, per vaginal discharge, wound infection around genital organs, lower abdominal pain in females. 
Table 3: Attitude towards STDs/HIV/AIDS among study population ( $\mathrm{N}=180)$

\begin{tabular}{|l|l|l|}
\hline \multicolumn{1}{|c|}{ Characteristics } & Frequency $(\mathrm{n})$ & Percentage (\%) \\
\hline $\begin{array}{l}\text { 1.Aware of any HIV/AIDS services available at your } \\
\text { workplace }\end{array}$ & 116 & 64.4 \\
Yes & 64 & 35.6 \\
No & & \\
\hline $\begin{array}{l}\text { 2.Willing to work with a co-worker who is HIV-positive } \\
\text { Yes }\end{array}$ & 129 & 71.7 \\
No & 51 & 28.3 \\
\hline $\begin{array}{l}\text { 3.Sexual knowledge should be included in school } \\
\text { curriculum }\end{array}$ & 171 & 95.0 \\
Yes & 9 & 5.0 \\
No & & \\
\hline
\end{tabular}

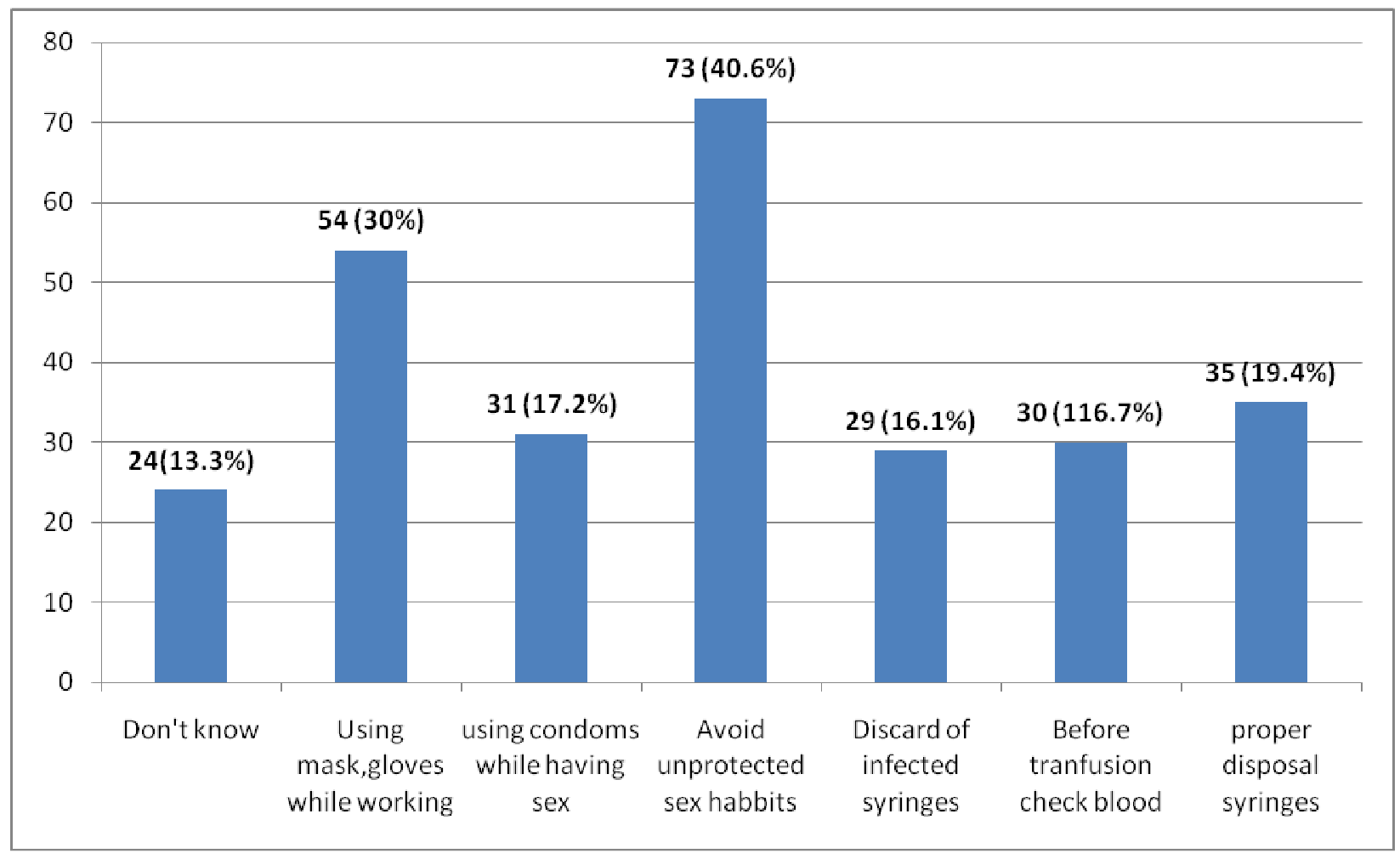

Fig 1: What do you do to prevent yourself from acquiring HIV/AIDS* 
Table.4: Practices towards STDs/HIV/AIDS among study population*

\begin{tabular}{|l|l|l|}
\hline \multicolumn{1}{|c|}{ Characteristics } & Frequency $(\mathrm{n})$ & Percentage (\%) $^{*}$ \\
\hline 1.Standard precaution methods you use in work & & \\
Proper uses and dispose of syringes & 13 & 7.2 \\
Using mask & 60 & 33.3 \\
Using gloves while handling & 65 & 36.1 \\
Wearing gluons and boot & 35 & 19.4 \\
Auto clamp of instrument & 7 & 3.9 \\
\hline 2. Advice you will give to your friends if you suspect & & \\
STDs & 124 & 68.9 \\
Go to the hospitals and treat & 26 & 14.4 \\
Go for Blood Test & 15 & 8.3 \\
Don't donate blood & 22 & 12.2 \\
Don't know & & \\
\hline
\end{tabular}

Table 3 and 4 shows the awareness and health services available for managing these conditions. Most of the study population knew that there are services available for HIV/AIDS in their workplace (64.4\%). Almost two thirds were willing to work with co-workers who were HIV-positive. 95\% agreed that sexual education must be included in the school curriculum. Avoiding unprotected sexual habits $(40.6 \%)$, using mask, gloves while working $(30 \%)$ and proper dispose of syringes (19.4\%) were listed as prevention strategies for HIV/AIDS. (see figure 1). Use of gloves while handing waste products of hospitals $(36.1 \%)$ and using mask while working in wards (33.3\%) were the commonest methods preferred for standard precautions. When we asked what advice you will give to your friends if you suspect STDs, majority suggested going to hospitals or other centres for management (83\%).

Table 5: Diagonal matrix correlations among variables

\begin{tabular}{|l|l|l|l|l|l|c|}
\hline \multirow{2}{*}{ Variables } & \multicolumn{2}{c|}{ Knowledge } & \multicolumn{2}{c|}{ Attitude } & \multicolumn{2}{c|}{ Practice } \\
\cline { 2 - 7 } & \multicolumn{1}{|c|}{$\mathrm{r}$} & $\mathrm{p}$ & $\mathrm{r}$ & $\mathrm{p}$ & $\mathrm{r}$ & $\mathrm{p}$ \\
\hline Age & -0.183 & 0.014 & -0.042 & 0.578 & -0.025 & 0.739 \\
\hline Years' work & 0.004 & 0.961 & 0.159 & 0.033 & -0.068 & 0.367 \\
\hline
\end{tabular}




\begin{tabular}{|l|l|l|l|l|l|l|}
\hline experiences & & & & & & \\
\hline Knowledge & 1.00 & - & 0.42 & $<0.001$ & 0.175 & 0.019 \\
\hline Attitude & 0.427 & $<0.001$ & 1.00 & - & 0.233 & 0.002 \\
\hline Practice & 0.175 & 0.019 & 0.233 & 0.002 & 1.00 & - \\
\hline
\end{tabular}

Correlation is significant at the 0.05 level (2-tailed).

Table 5 shows the relationship among knowledge, attitude, and practice with age, and work experiences of respondents. Correlation analysis with age showed a negative relationship position knowledge $(r=-$ $0.183)$, attitude $(r=-0.042)$, practices $(r=-$ 0.025). Years of experiences had positive relation with knowledge $(r=0.004)$, attitude $(r=0.159)$ but showed negative relationship with practices $(r=-0.068)$ but correlation with attitude $(p=0.033)$ and practices $(p=0.367)$ was significant.

\section{Discussion}

The objective of the study was to assess knowledge, attitude and practice towards STDs among health attendant staffs (health aids and health attendants) of BPKIHS. The response rate was $90 \%$. Majority of the study population were from the age group 30-34 years with mean age of the study population was 36.77 years and having 14 years of experience working time and majority were literate. It indicates the predominant workers are young and are literate.

The results of this survey indicate that people were aware that it was knowledge about infectious disease. The knowledge about condom as a preventive strategy was high among health attendants. The knowledge about routes of transmission was satisfactory among them. Most the study respondents said that STDs/HIV/AIDS can transmit to others by unprotected sex and through blood transmission. More than $86 \%$ study population knew about the STDs/HIV/AIDS. These findings supports the result of Behaviours Surveillance Surveys under taken by NACO (NACO-2001), Ganguli et al. (2002) ${ }^{15}$, Kumar et al. (1996) ${ }^{16,}$ Singh et al., (2002) ${ }^{17}$. The study done in China by $\mathrm{Wu}$ zet $\mathrm{al}^{18}$ showed that knowledge about route of transmission was low among health workers.

In our study majority of the respondents had aware about the services provided in institution and it is good to hear that they are willing to work with co-workers who are HIV positive, which shows good attitude amongst health attendants and they eagerly told that sexual education must include in school level, so that their children can know about this types of disease and infection. In study done by Timilshina $\mathrm{N}$ et $\mathrm{al}^{19}$ among auxiliary health workers including nurses showed that there 
was significant difference in health workers perceptions about people living with HIV/AIDS and many health workers would not like to operate on HIV/AIDS.

In our study majority had knowledge about the preventive methods to protect from STD/HIV/AIDS. More than half of the study population expressed that avoiding multiple sex partners and wearing gloves and mask while handling waste materials are the most preventive methods. The study done Sadob A.E et.al ${ }^{20}$ among health care workers showed that most of the study population had knowledge and preventive about HIV/AIDS.

Correlation of level of health attendants' knowledge, attitude and practices showed that increasing age had lesser level of knowledge and not negative attitude about STD/HIV/AIDS patients. Although the practices were not found to be satisfactory among higher age group, it was not statistically significant. Increasing year of experiences can have better attitude towards STDs/HIV/AIDS. The study done by Mulaudzi1 M V et.al. ${ }^{13}$, showed that about $77 \%$ nurses had positive attitude caring for HIV/AIDS patient, while $6 \%$ had very negative attitude. The study done by SadobA. $E^{20}$ showed that, health worker had positive attitude towards HIV/AIDS patient if the source of infection was from blood transfusion and from infected mother to baby. This study was based on a sample of health attendant staffs in a single hospital of B.P.
Koirala Institute of Health Sciences, Dharan in Sunsari districts of Eastern Nepal, which limits the generalization of the results. Regardless, these findings raise concerns about health attendant' knowledge, attitudes and practices in STDs/HIV/ AIDS.

\section{Conclusion}

In conclusion, majority of study population were ages 30-44 years group, majority had good knowledge about STDs/HIV/AIDS. Most of them had worked in BPKIHS about 15 years. About two third were willing to work with a co-worker who is HIV-positive. Finally, the study population had basic knowledge about the STDs/HIV/AIDS but with growing working experiences they are neglecting the safety practices methods while working. Some of the respondents still hesitated to answers on STDs/HIV/AIDS issues.

\section{References}

1. Ainbinder SW, Ramin SM, DeCherney $\mathrm{AH}$. Sexually transmitted diseases \& pelvic infections. In: DeCherney $\mathrm{AH}$, Nathan L, Goodwin TM, Laufer N, editors. Current diagnosis \& treatment Obstetrics \& Gynecology. 10th edition. USA: The McGaw-Hill Companies, Inc., 2007.

2. Adadevoh SWK, editor. National Adolescent Health \& Development Programme - Training manual for 
healthcare providers in Ghana. First edition. Accra: Ghana Health Service, United Nations Population Fund (UNFPA), Ghana Ministry of Health, 2005.

3. WHO, UNAIDS. Sexually transmitted diseases: policies and principles for prevention and care.1999.

4. The public health approach to STD control. From UNAIDS Technical Update May 1998. (Online)(Cited 2008 Oct 13). Available from URL: http://www.who.int/hiv/pub/sti/en/stdcont rol_en.pdf

5. New Era/Ministry of Health. Nepal demographic and health survey. Kathmandu: New era/Ministry of Health; 2006.

6. Puri M. sexual risk behaviour and risk perception of unwanted pregnancies and sexually transmitted diseases among young factory workers in Nepal. Kathmandu: Center for Research on environment health and population activities; 2001.

7. UNAIDS. AIDS epidemic update: December 2005. Geneva: Joint united nations programme on HIV/AIDS; 2005.

8. Onah HE, Mbah AU, Chukwuka JC, Ikeme AC. HIV/AIDS awareness and sexual practices among undergraduates in Enugu, Nigeria. Nigerian
Postgraduate Medical Journal. 2004; 11(2):121-125.

9. Keller SE, Bartlett JA, Schleifer A, Johnson RL, Pinner E, Delaney B. HIV relevant sexual behavior among a healthy inner city heterosexual adolescent population in an endemic area of HIV. Journal of Adolescent Health Care. 1991; 12:44-48.

10. Diclemente RJ. Predictors of HIVpreventive sexual behavior in a highrisk adolescent population: the influence of perceived peer norms and sexual communication on incarcerated adolescents' consistent use of condoms. Journal of Adolescent Health. 1991; 12(5):385-390.

11. Hingson R, Strunin L, Berlin B. Acquired immunodeficiency syndrome transmission: Changes in knowledge and behaviours among teenagers. Massachusetts Statewide Surveys, 1986 to 1988. Pediatrics. 1990; 85:2429.

12. Hussai M F A, Siddiqui S E, Manzar N, Raza S, Qama S. Knowledge, Attitudes \& Practices (KAP) of General Practitioners (GPs) regarding Sexually Transmitted Diseases (STDs) and HIV/ AIDS in Karachi, Pakistan. JPMA 61:202; 2011

13. Mulaudzi1 M V, Pengpid S, Peltzer K Nurses' Knowledge, Attitudes, and 
coping Related to HIV and AIDS in a Rural Hospital in South Africa Ethno Med., 2011;5(1): 25-32.

14. Upreti D, Regmi P, Pant P, Simkhada P. Young people's knowledge, attitude, and behaviour on STI/HIV/AIDSin the context of Nepal: A systematic review. Kathmandu University Medical Journal (2009;7(4): 28:383-391

15. Ganguli SK, Rekha PP, Gupta N, Charan UA. AIDS awareness among undergraduate's students in Maharastra. Ind J Pub Health 2002; 46(1): 8-12.

16. Kumar A., Lal P., Ingle G.K. \& Gulati N. (1999) AIDS-related apprehensions among nursing students of Delhi. Journal of Communicable Diseases. 1999; 31(4), 217-221.
17. Singh S, Fukuda H, Ingle GK, Tatara K. Knowledge, and attitude the perceived risks of infection and the source of information about HIV/AIDS among pregnant women in an urban population of Delhi. J. Common Dis 2002; 34(1): 23-33.

18. Wu Z, Qi G, Zeng $\mathrm{Y}$, Derels $\mathrm{R}$. Knowledge of HIV/AIDS among Health care workers in China. AIDS Education and Prevention, 1999;11(4):353-363

19. Timilshina N,1 Ansari MA2. Knowledge and Attitude of Basic Health Workers (BHWs) toward HIV/AIDS .J Nepal Health Res Council 2013;11(24):182-6

20. SadobA.E. Fawolea, Sadob W.E., Oladimeji A.O, Satilove O. S. Attitude of health-care Workers to HIV/AIDS. African journal of reproductive health 2006;10(1):39-46. 